\title{
Methicillin/Oxacillin-resistant Staphylococcus aureus \\ as a hospital and public health threat in Brazil
}

\begin{abstract}
Methicillin-resistant Staphylococcus aureus is an established nosocomial pathogen (HA-MRSA, hospital acquired MRSA), but has recently begun to appear in the community (CA-MRSA, community acquired MRSA). The cause of resistance to methicillin and all other $\beta$-lactam antibiotics is the mecA gene, which is situated on a mobile genetic element, the Staphylococcal Cassette Chromosome mec (SCCmec). Seven major variants of SCCmec, type I to VII are distinguished. HA-MRSA disseminated worldwide and causes the majority of $S$. aureus nosocomial infections with a limited number of clones disseminated including the Brazilian Epidemic Clone (BEC, ST239-MRSA-III). CA-MRSA isolates are susceptible to non- $\beta$-lactam antibiotics, usually isolated from healthy individuals which do not possess any unknown risk factors for MRSA infection and are associated with a larger clonal diversity compared with HA-MRSA. However, during recent years distinction between HA-MRSA and CA-MRSA is beginning to fade. Actually, knowledge about MRSA disseminating clones is required to implement any strategies to control the transmission of MRSA either within hospitals or in community. For this reason, rapid identification of strains is an important issue. The rate of HAMRSA can be reduced substantially through the implementation of interventions strategies, even in settings where MRSA is endemic as in most Brazilian hospitals. However, these policies could be quite complicated in the light of an increasing CA-MRSA prevalence in healthcare facilities, considering that distinction between HA-MRSA and CA-MRSA has started to disappear.
\end{abstract}

Keywords: methicillin-resistant Staphylococcus aureus, community acquired methicillin-resistant Staphylococcus aureus, nosocomial infections and community infections.

[Braz J Infect Dis 2010;14(1):71-76] @Elsevier Editora Ltda.

\section{INTRODUCTION}

Staphylococcus aureus has been recognized as an important pathogen associated with inpatients and community infections. ${ }^{1}$ As soon as methicillin was marketed in 1960 , resistant isolates were reported after the screening of clinical isolates in England. ${ }^{2}$ By 1967 MRSA was reported from Switzerland, France, Denmark, Australia and India ${ }^{3}$ and mainly in the early 1980s multidrugresistant MRSA was reported from several countries ${ }^{4}$ and now is currently endemic in various hospitals worldwide, ${ }^{5}$ mainly in developing countries as Brazil. ${ }^{6,7}$

Many studies have identified MRSA strains that appear to be well adapted to the hospital environment ${ }^{8}$ frequently isolated from bacteremia, wound infections and pneumonia. ${ }^{1}$ Risk factors for the acquisition of hospital infection caused by this MRSA comprehend: indwelling devices, prolonged hospitalization, and long-term antibiotic use. MRSA transmission occurs via person-to-person spread by healthcare staff hands and via environmentto-patient spread. ${ }^{1}$

In 1993, novel MRSA strains were reported from Indigenous Australian patients who had not been previously exposed to the health-care system. ${ }^{9}$ Community-associated methicillinresistant Staphylococcus aureus (CA-MRSA) has emerged worldwide during 80 's and has been described as an endemic pathogen in USA, Europe and Australia. These genuine community acquired MRSA strains, which were transmitted in the community and differed from conventional endemic nosocomially acquired MRSA strains in several ways, ${ }^{1}$ including: they were more susceptible to antibiotic classes other than $\beta$-lactam antibiotics, ${ }^{10}$ their geno-

\section{Authors}

Karinne Spirandelli Carvalho

Elsa Masae Mamizuka ${ }^{2}$ Paulo P Gontijo Filho ${ }^{3}$

${ }^{1}$ Universidade Federal de Uberlândia

${ }^{2}$ Universidade de São Paulo ${ }^{3}$ Universidade Federal de Uberlândia
Submitted on: 09/06/2009 Approved on: 12/08/2009

Correspondence to: Karinne Spirandelli Carvalho Immunology and Parasitology Fellowship Program

Universidade Federal de Uberlândia

Av. Pará no 1720 Bloco C - Campus Umuarama CEP: 38400-902

We declare no conflict of interest. 
types were not the same as isolates from hospitals, ${ }^{11}$ they mainly harbored different methicillin-resistance cassettes, ${ }^{12}$ and finally, community isolates were more likely do encode a putative virulence factor called Panton-Valentine leukocidin. ${ }^{13}$ In general, CA-MRSA is more virulent compared to HA-MRSA due to presence of various virulence factors. ${ }^{14,15}$

Even since this recognition, community acquired MRSA has been isolated from children and adults with skin and soft tissue infections, septic arthritis, bacteremia, toxic shock syndrome, necrotizing fasciitis, and necrotizing pneumonia. ${ }^{16,17}$ It has been reported most often from indigenous populations, homeless people, jailed inmates, military recruits, children in day care centers and competitors athletes. ${ }^{18}$ Common to all these groups is a high intensity physical contact which might help with transmission. ${ }^{1}$

Not unexpectedly, community-acquired MRSA has also found its way into hospitals where outbreaks have been reported $^{19}$ but most of these infections were restricted to patients with frequent contact with health facilities, such as residents of long-term care facilities and intravenous-drug users. ${ }^{20}$ Several recent reports have described the transmission of this pathogen establishing a new nosocomial risk witch needs to be considered by infection control professionals. ${ }^{1}$ The first reported cases in Brazil, were in the Hospital das Clínicas of University of São Paulo, involving bloodstream infections caused by non-multiresistant oxacillin-resistant Staphylococcus aureus, SCCmec IV. ${ }^{21}$ The emergence in Brazil of methicillin-resistant Staphylococcus aureus isolates carrying SCCmec IV, genetically related to the USA800 clone, was reported by Miranda et al. (2007) 22 in hospitals in two cities, without considerations about the patients / medical records evidence of risk factors. Recently, the same group ${ }^{23}$ reported that some of these isolates $(5 / 13,32.8 \%)$ were characterized as CA-MRSA both by molecular characteristics and clinical origin, including outpatients who had not been hospitalized. Using gentamicin, chloramphenicol, rifampicin and trimethoprim-sulphamethoxazole as a phenotypic marker was reported by us, ${ }^{24}$ with only $13.6 \%$ of the MRSA infections were classified epidemiologically "as CA-MRSA infections" in 24 patients with medical record evidence of risk factors as invasive devices and hospitalization. CA-MRSA in the absence of classic risk factors for MRSA diseases has also been reported by Ribeiro et al. $(2007)^{25}$ with the presence of international CA-MRSA clones in Rio de Janeiro and Porto Alegre encoding PVL genes. CA-MRSA SCCmec IV as cause of infection in hospitalized patients was also reported by Reinert et al. (2008) $)^{26}$ in three out 50 nosocomial strains obtained from a previous study in São Paulo.

Since the 90s, virulent community-associated MRSA (CA-MRSA) clones, spread worldwide, first in the community, but later also in healthcare facilities. At the moment, the restriction between CA-MRSA and HA-MRSA is beginning to fade. ${ }^{27,28}$

\section{Worldwide and Brazilian burden of HA-MRSA}

Presently, MRSA is the most commonly identified antibiotic-resistant pathogen in many parts of the world, including Europe, the Americas, North Africa, the Middle East and East Asia. It is a common hospital pathogen and cause severe infections in which its multiple antibiotic resistance is a serious complication. ${ }^{25}$ MRSA rates have been increasing worldwide over the past decades, as data from continuing surveillance initiatives such as the National Nosocomial infection Surveillance System and European Antimicrobial Resistance Surveillance System. ${ }^{29,30}$ It was observed that MRSA prevalence was 23\% in Australia, 67\% in Japan, 40\% in South Pacific, $32 \%$ in USA, and $26 \%$ in Europe. ${ }^{31} \mathrm{~A}$ limited number of MRSA clones are disseminating worldwide each of them with a specific genetic background and SCCmec type. ${ }^{32}$

There is evidence that hospital-acquired MRSA infection increases morbidity, mortality risk and costs..$^{33}$ In Brazil, data from the first five years of SENTRY Antimicrobial Surveillance Program ${ }^{6}$ MRSA correspond to $56 \%$ of nosocomial and community infections evaluated and was the most common among prevalent pathogens.

According to data from Hospital de Clínicas from Federal University of Uberlândia MRSA correspond to $63.7 \%$ of blood infection, $100 \%$ of urinary tract infection and $46.7 \%$ of Ventilator-Associated Pneumonia (VAP) caused by Staphylococcus aureus. ${ }^{7}$ Moreira e Gontijo Filho $(2008)^{34}$ researching the VAP's etiology in the adult critical care unit of the same hospital reported $41.2 \%$ of $S$. aureus isolates with $41.2 \%$ of MRSA.

\section{Resistance determinants and Staphylococcal Cassettes Chromosome mec (SCCmec)}

The understanding of the evolution of MRSA has benefited from the development of molecular methods that provide characterization of both the strain phylogeny and the methicillin-resistance determinant. Consistent molecular epidemiological evidence supports the view that the evolution of MRSA and of S. aureus as a species is predominantly clonal, but as in others organisms horizontal transfer of DNA from other strains or species occurs and plays an important part in resistance acquisition in S. aureus and is brought about mainly by insertion of insertion sequences, transposons, prophages, and incompletely understood events. ${ }^{35}$ MRSA originates from the introduction of a large mobile genetic element called SCCmec into a methicillin-susceptible $S$. aureus strain. ${ }^{36}$

The mecA gene which encodes an additional penicillin-binding protein (PPP2A) with reduced affinity of $\beta$-lactam antibiotics is located on a mobile genomic island, called Staphylococcal cassette chromosome mec (SCCmec). ${ }^{37}$ At the moment seven main types of SCCmec (type I to VII) are recognized. Types IV, V, VI and VII, cause only b-lactam antibiotic resistance while SCCmec 
I, II and III cause resistance to multiple classes of antibiotic, due to additional drug resistance genes integrated into SCCmec, i.e. integrated plasmids and transposons. ${ }^{38}$ For its mobilizations SCCmec carries specific genes designated cassette chromosome recombinases $(c c r \mathrm{~A}, c c r \mathrm{~B}$ or $c c r \mathrm{C}) .{ }^{39}$ The Brazilian/Hungarian clone correspond to SCCmec III, ST 239 and MLST profile 2-3-1-1-4-4-3. ${ }^{40}$

\section{Origins, reservoirs and distribution of SCCmec types}

There are several lines of evidence about the origin of SCCmec but is know that methicillin resistance is highly prevalent in S. epidermidis isolates (over 70\%) and less common in $S$. aureus suggesting that $S$. epidermidis is the reservoir for SCCmec. ${ }^{40}$

Health-care associated and community-acquired MRSA strains have been proved genetically distinct with respect to the SCCmec type they contain, and most health-care associated MRSA strains carry one of three types of SCCmec (type I, II, or III). ${ }^{8}$ whereas most community-acquired MRSA strains carry mainly SCCmec type IV. Type V has also been identified in community-acquired MRSA isolates. ${ }^{11}$ The extreme heterogeneity of the genetic backgrounds in community-acquired MRSA strains and the small size of SCCmec types IV and V suggests that these SCCmec allotypes are more readily transmissible between staphylococci than the larger SCCmec types and, once introduced do no compromise the fitness of the pathogen. ${ }^{39,41}$

MRSA nomenclature is currently based on the Multilocus Sequence Typing (ST) of fragments of seven housekeeping genes that refers the $S$. aureus lineage, resulting in an allelic profile designated ST, and the type of SCCmec element. ${ }^{32}$ The detection of divergent MRSA lineages by different molecular typing techniques, including Multilocus Sequence Typing (MLST) suggests, as previously mentioned, that MRSA have arisen by the introduction of SCCmec into distinct successful methicillin-susceptible $S$. aureus lineages. ${ }^{42,43}$

It was recently reported that approximately $50 \%$ of MRSA isolates recovered from skin/soft tissue infections in the United States belonged to a CA-MRSA clone called USA300 (SCCmecIV, ST8, lukSF+). ${ }^{44}$ Ribeiro et al. $(2007)^{23}$ reported a diversity of clones isolated from Porto Alegre and Rio de Janeiro including USA300, Ocean South Pacific Clone (OSPC) e USA400 corresponding to tree clonal complex: ST8, ST30 and ST1 respectively.

Furthermore, the larger clonal diversity of CA-MRSA compared to HA-MRSA suggests that more $S$. aureus lineages is able to become CA-MRSA. ${ }^{45}$ In spite of the majority of the CA-MRSA isolates harbor SCCmec type IV, V or VII, ${ }^{46}$ several studies have also observed CA-MRSA harboring SCCmec type I, II or III. ${ }^{47}$ However, the majority of the studies have concluded that PVL, together with SCCmec type IV or V and specific genetic background, is a genetic marker for CA-MRSA. ${ }^{48}$
Until recently, it was believed that the dissemination of PVL-positive CA-MRSA clones was related to components, i.e. the ST1 and ST 8 clone in USA and the ST 80 clone in Europe ${ }^{49}$ Recent studies have shown that this observation is starting to change. Today, five major PVL-positive CA-MRSA clones is observed worldwide: ST1 clone is observed in Asia, Europe and the USA, ST30 clone in Australia, Europe and South America, and largest diversity of CA-MRSA clones in countries with numerous international exchanges, such as travel hubs. ${ }^{32}$

\section{Control of MRSA}

\section{SCREENING OF PATIENTS}

Colonized and infected patients represent the most important reservoir of MRSA in health-care facilities..$^{50}$ Culture from body sites such as the anterior nostrils alone will identify $80 \%$ of patients colonized with MRSA.${ }^{51}$ These patients, who do not have clinically evident infection but are carriers of MRSA, can serve as reservoirs from which the organism is transmitted to other patients. ${ }^{52}$ On the basis of the evidence available, several published guidelines have recommended screening of inpatients at high risk of carrying MRSA, as those admitted to intensive-care-wards. ${ }^{53}$

\section{ISOLATION AND BARRIER NURSING}

Patients colonized or infected with MRSA should whenever possible be housed with other patients who have MRSA, ${ }^{53,54}$ measure that is no realistic in Brazilian hospitals. Effectiveness of the use of gloves and gowns to care for patients with MRSA has been established in epidemiological studies, ${ }^{55}$ although there is no randomized trials supporting their use, ${ }^{56}$ so contact precautions are not effective in interrupting transmission of endemic MRSA. ${ }^{57}$

\section{ENVIRONMENTAL CLEANING}

How important are contaminated environmental surfaces as a reservoir for MRSA? The US Centers for Disease Control and Prevention isolation guidelines recommend that hospitals have adequate procedures for routine care, cleaning, and disinfection of environmental surfaces frequently touched..$^{58}$ Further studies are needed to find out if thorough decontamination of rooms occupied by patients with MRSA will affect MRSA transmission rates. ${ }^{57}$

\section{HAND HYGIENE}

Transient contamination of health-care workers` hands has been documented on many occasion $s^{50}$ and is widely believed to be the predominant method by which MRSA is transmitted to patients.

\section{DECOLONIZATION THERAPY}

Widespread use in a hospital or long-term use of mupirocin in patients should be avoided since these practices have been associated with emergence of mupirocin-resistant strains of MRSA. ${ }^{59,60}$ 
However, comprehensive MRSA-control program that have included screening cultures to detect patients colonized with MRSA, use of contact precautions, appropriate hand hygiene, automatic alerts of readmission of colonized patients, with or without decolonization of colonized individual, have reported success in controlling or reducing transmission of MRSA nationally, regionally, and institutionally. ${ }^{52}$

\section{CONCLUSIONS}

Guidelines have suggested that alternatives to $\beta$-lactams antibiotics be used as empirical therapy for patients presenting with SSTIs in areas were the prevalence of CA-MRSA exceeds 10 to $15 \%{ }^{61}$ However, $\beta$-lactams antibiotics continue to be prescribed empirically to a great proportion of patients who have an infection with CA-MRSA. ${ }^{62}$ Although some studies have found that the use of an inactive antimicrobial regimen for CA-MRSA infection is not necessarily associated with adverse outcomes, more-recent data suggest that there is a difference in clinical cure rates based on adequacy of the antibiotic prescribed. ${ }^{63}$

The present success of the few pandemic hospitalacquired-MRSA clones has been accounted for by the acquisition of additional fitness traits by already widespread and successful colonizing strains, with the view that gaining $\beta$-lactam resistance yields a decisive advantage over competitors in hospitals. ${ }^{8}$ Because of the higher pathogenicity of community strains, community acquired MRSA in hospitals could change its predominantly opportunistic behavior and cause infections in patients who are no seriously ill or even in health-care workers. ${ }^{64}$ The recently published genome sequence of another very successful clone of communityacquired MRSA, USA300, lends further support to the theory that successive genomic alterations led to the evolution of fitter clones that combine antimicrobial resistance with transmissibility and virulence. ${ }^{65}$ In spite that is often thought that CA-MRSA and HA-MRSA belong to different lineages within a geographic area, and the proportion of CA-MRSA is an increasing trend there is also evidences that the distinction between these two organisms is beginning to fade. If the new community-acquired MRSA clones are, however, sufficiently fit to sustain endemic levels by transmission in the community, the MRSA situation in hospitals still remains out of control in many countries as Brazil and could potentially become explosive.

\section{REFERENCES}

1. Millar BC, Loughrey A, Elborn JS, Moore JE. Proposed definitions of community-associated meticillin-resistant Staphylococcus aureus (CA-MRSA). J Hosp Infect 2007; 67:109-13.

2. Jevons MP. "Celbenin" - resistant Staphylococci. BMJ 1961; $1: 124-5$
3. Parker MT, Hewitt JH. Methicillin resistance in Staphylococcus aureus. Lancet 1970; 1:800-4.

4. Boyce JM, White RL, Apruill EY. Impact of methicillin-resistant Staphylococcus aureus on the incidence of nosocomial staphylococcal infections. J Infect Dis 1983; 148(4):763.

5. Trindade PA, McCulloch JA, Oliveira GA, Mamizuka EM. Molecular Techniques for MRSA Typing: Current Issues and Perspectives. Braz J Infect Dis 2003; 7(1):32-43.

6. Sader H, Jones RN, Gales AC, Silva JB, Pignatari AC and the SENTRY participants. SENTRY Antimicrobial Surveillance Program Report: Latin America and Brazilian results for 1997 through 2001. Braz J Infect Dis 2004; 8(1):25-79.

7. Carvalho RH. Bactérias resistentes e multirresistentes a antibióticos nos pacientes internados em uma UTI de adultos de hospital universitário brasileiro. Uberlândia, 2007. 38p. Dissertação (Mestrado em Imunologia e Parasitologia Aplicadas) - Programa de Pós-Graduação em Imunologia e Parasitologia Aplicadas - Universidade Federal de Uberlândia, 2007.

8. Enright MC, Robinson DA, Randle G, Feil EJ, Grundmann H, Spratt BG. The evolutionary history of methicillin-resistant Staphylococcus aureus (MRSA). Proc Natl Acad Sci U S A 2002; 99(11):7687-92.

9. Udo EE, Pearman JW, Grubb WB. Genetic analysis of community isolates of methicillin-resistant Staphylococcus aureus in Western Australia. J Hosp Infect 1993; 25:97-108.

10. Herold BC, Immergluck LC, Maranan MC et al. Communityacquired methicillin-resistant Staphylococcus aureus in children with no identified predisposing risk. JAMA 1998; 279:593-98.

11. Vandenesch F, Naimi E, Enright MC et al. Community-acquired methicillin-resistant Staphylococcus aureus carrying Panton-Valentine leukocidin genes: worldwild emergence. Emerg Infect Dis 2003; 9:978-84.

12. Okuma K, Iwakawa K, Turnidge JD et al. Dissemination of new methicillin-resistant Staphylococcus aureus clones in the community. J Clin Microbiol 2002; 40:4289-94.

13. Dufour P, Gillet $\mathrm{Y}$, Bes M et al. Community-acquired methicillin resistant Staphylococcus aureus infections in France: emergence of a single clone that produces Panton-Valentine leukocidin. Clin Infect Dis 2002; 35:819-24.

14. Chambers HF. The changing epidemiology of Staphylococcus aureus? Emerging Infectious Diseases 2001; 7(2):178-82.

15. Etienne J. Panton-Valentine leukocidin: a marker of severity for Staphylococcus aureus infection? Clin Infect Dis 2005; 41:591-3.

16. US Centers for Disease Control and Prevention. Four pediatric deaths from community-acquired methicillin-resistant Staphylococcus aureus - Minnesota and North Dakota, 1997 1999. MMWR Morb Mortal Wkly Rep 1999; 48:707-10.

17. Gillet Y, Issartel B, Vanhems P et al. Association between Staphylococcus aureus strains carrying gene for Panton-Valentine leukocidin and highly lethal necrotising pneumonia in young immunocompetent patients. Lancet 2002; 359:753-9.

18. US Centers for Disease Control and Prevention. Methicillinresistant Staphylococcus aureus infections among competitive sports participants - Colorado, Indiana, Pennsylvania, and Los Angeles Country, 2000-2003. MMWR Morb Mortal Wkly Rep 2003; 52:793-5. 
19. Cunha BA. A useful clinical approach to community-acquired methicillin-resistant Staphylococcus aureus CA-MRSA infections. J Hosp Infect 2008; 68(3):271-2.

20. Levine DP, Cushing RD, Jui J, Brown WJ. Community-acquired methicillin-resistant Staphylococcus aureus endocarditis in the Detroit Medical Center. Ann Intern Med 1982; 97:330-8.

21. Trindade PA, Pacheco RL, Costa SF, et al. Prevalence of SCCmec type IV in nosocomial bloodstream isolates of methicillin-resistant Staphylococcus aureus. J Clin Microbiol 2005; 43:3435-7.

22. Miranda OP, Silva-Carvalho MC, Ribeiro A et al. Emergence in Brazil of methicillin-resistant Staphylococcus aureus isolates carrying SCCmecIV that are related genetically to the USA800 clone. Clin Microbiol Infect 2007; 13:1165-72.

23. Ribeiro A, Coronado AZ, Silva-Carvalho MC et al. Detection and characterization of international community-acquired infections by methicillin-resistant Staphylococcus aureus clones in Rio de Janeiro and Porto Alegre cities causing both community- and hospital-associated diseases. Diagn Microbiol Infect Dis 2007; 59:339-45.

24. Carvalho KS, da Trindade NV, Gontijo Filho PP. Aspectos microbiológicos e epidemiológicos de infecções por MRSA suspeitas de CA-MRSA adquiridas em um hospital universitário brasileiro. In: Program and abstracts: III Congresso Mineiro de Infectologia Belo Horizonte, 2008.

25. Kluitmans J, Van Belkum A, Verbrugh H. Nasal carriage of Staphylococcus aureus: epidemiology, underlying mechanisms and associated risks. Clin Microbiol Rev 1997; 10:505-20.

26. Reinert C, McCulloch JA, Watanabe S, Ito T, Hiramatsu K, Mamizuka EM. Type IV SCCmec found in decade old Brazilian MRSA isolates. Braz J Infect Dis 2008; 12(3):213-6.

27. Lowy FD. Staphylococcus aureus infections. N. Engl. J. Med 1998; 339:520-32.

28. Lowy FD. Antimicrobial resistance: the example of Staphylococcus aureus. J Clin Invest 2003; 111:1265-73.

29. Fridkin SK, Hill HA, Volkova NV et al. Intensive Care Antimicrobial Resistance Epidemiology Project Hospitals. Temporal changes in prevalence of antimicrobial resistance in 23 US hospitals. Emerg Infect Dis 2002; 8:697-701.

30. Tiemersma EW, Bronzwaer SL, Lyytikainen O et al. European antimicrobial resistance surveillance system participants. Methicillin-resistant Staphylococcus aureus in Europe, 1999-2002. Emerg Infect Dis 2004; 10:1627-34.

31. Diekema DJ, Pfaller MA, Schmitz FJ et al. Survey of infections due to Staphylococcus species: frequency of occurrence and antimicrobial susceptibility of isolates collected in the United States, Canada, Latin America, Europe, and the Western Pacific region for the SENTRY Antimicrobial Surveillance Program, 1997-1999. Clin Infect Dis 2001; 32(Suppl. 2): S114-32.

32. Deurenberg RH, Stobberingh EE. The evolution of Staphylococcus aureus. Infection, Genetics and Evolution 2008; 8(6):747-763.

33. Cosgrove SE, Qi Y, Kaye KS, Harbarth S, Karchmer AW, Carmeli Y. The impact of methicillin resistance in Staphylococcus aureus bacteremia on patient outcomes: mortality, length of stay, and hospital charges. Infect Control Hosp Epidemiol 2005; 26:166-74.
34. Moreira MR, Cardoso RL, Almeida AB, Gontijo Filho PP. Risk factors and evolution of Ventilator-associated pneumonia by Staphylococcus aureus sensitive or resistant to Oxacillin in patients at Intensive Care Unit of a Brazilian University Hospital. Braz J Infect Dis 2008; 12(6):499-503.

35. Robinson DA, Enright MC. Evolution of Staphylococcus aureus by large chromosomal replacements. J Bacteriol 2004; 186:1060-4.

36. Hartman B, Tomasz A. Altered penicillin-binding proteins in methicillin-resistant strains of Staphylococcus aureus. Antimicrob Agents Chemother 1981; 19:726-35.

37. Ito T, Okuma K, Ma XX, Yuzawa H, Hiramatsu K. Insights on antibiotic resistance of Staphylococcus aureus from its whole genome: genomic island SCC. Drug Resist Updat 2003; 6:4152.

38. Oliveira DC, Tomasz A, de Lencastre H. The evolution of pandemic clones of methicillin-resistant Staphylococcus aureus: identification of two ancestral genetic backgrounds and the associated mec elements. Microb Drug Resist 2001; 7:349-61.

39. Ito T, Ma XX, Takeuchi F, Okuma K, Yuzawa H, Hiramatsu K. Novel type V staphylococcal cassette chromosome mec driven by a novel cassette chromosome recombinase, ccrC. Antimicrob Agents Chemother 2004; 48:2637-51.

40. Wielders CL, Vriens MR, Brisse S et al. In-vivo transfer of mecA DNA to Staphylococcus aureus. Lancet 2001; 357:1674-5.

41. Ito T, Katayama Y, Asada K et al. Structural comparison of three types of staphylococcal cassette chromosome mec integrated in the chromosome in methicillin-resistant Staphylococcus aureus. Antimicrob Agents Chemother 2001; 45:132336.

42. Robinson DA, Enright MC. Evolutionary models of the emergence of methicillin-resistant Staphylococcus aureus. Antimicrob Agents Chemother 2003; 47: 3926-34.

43. Enright MC. The evolution of a resistant pathogen - the case of MRSA. Curr Opin Pharmacol 2003; 3:474-9.

44. Moran GJ, Krishnadasan A, Gorwitz RJ, Fosheim GE, McDougal LK, Carey RB et al. Emergency Id Net Study Group (2006) Methicillin-resistant $S$. aureus infections among patients in the emergency department. N Engl J Med 2006; 355:666-74.

45. Enright MC, Robinson DA, Randle G, Feil EJ, Grundmann H, Spratt BG. The evolutionary history of methicillin-resistant Staphylococcus aureus (MRSA). Proc Natl Acad Sci U.S.A 2002; 99:7687-92.

46. Takano T, Higuchi W, Otsuka T et al. Novel characteristics of community-acquired methicillin-resistant Staphylococcus aureus belonging to multilocus sequence type 59 in Taiwan. Antimicrob Agents Chemother 2008; 52:837-45.

47. Wannet WJ, Spalburg E, Heck ME et al. Emergence of virulent methicillin-resistant Staphylococcus aureus strains carrying Panton-Valentine leukocidin genes in The Netherlands. J Clin Microbiol 2005; 43:3341-5.

48. Tristan A, Bes M, Meugnier $\mathrm{H}$ et al. Global distribution of Panton-Valentine leukocidin-positive methicillin-resistant Staphylococcus aureus, 2006. Emerg Infect Dis 2007; 13:594600.

49. Vandenesch F, Naimi T, Enright MC, et al. Community-acquired methicillin-resistant Staphylococcus aureus carrying Panton-Valentine leukocidin genes: worldwide emergence. Emerg Infect Dis 2003; 9:978-84. 
50. Girou E, Pujade G, Legrand P, Cizeau F, Brun-Buisson C. Selective screening of carriers for control of methicillin-resistant Staphylococcus aureus (MRSA) in high-risk hospital areas with a high level of endemic MRSA. Clin Infect Dis 1998; 27:54350 .

51. Lucet JC, Chevret S, Durand-Zaleski I, Chastang C, Regnier B. Prevalence and risk factors for carriage of methicillin-resistant Staphylococcus aureus at admission to the intensive care unit: results of a multicenter study. Arch Intern Med 2003; 163:181-8.

52. Jernigan JA, Titus MG, Groschel DH, Getchell-White S, Farr BM. Effectiveness of contact isolation during a hospital outbreak of methicillin-resistant Staphylococcus aureus. Am J Epidemiol 1996; 143:496-504.

53. Coia JE, Duckworth GJ, Edwards DI et al. Joint Working Party of the British Society of Antimicrobial Chemotherapy; Hospital Infection Society; Infection Control Nurses Association. Guidelines for the control and prevention of meticillin-resistant Staphylococcus aureus (MRSA) in healthcare facilities. J Hosp Infect 2006; 63S:S1-44.

54. British Society for Antimicrobial Chemotherapy, Hospital Infection Society and the Infection Control Nurses Association. Revised guidelines for the control of methicillin-resistant Staphylococcus aureus infection in hospitals. J Hosp Infect 1998; 39:253-90.

55. Pittet D, Dharan S, Touveneau S, Sauvan V, Perneger TV. Bacterial contamination of the hands of hospital staff during routine patient care. Arch Intern Med 1999; 159:821-6.

56. Boyce JM, Potter-Bynoe G, Chenevert C, King T. Environmental contamination due to methicillin-resistant Staphylococcus aureus: possible infection control implications. Infect Control Hosp Epidemiol 1997; 18:622-7.

57. Grundmann H, Aires-de-Sousa M, Boyce J, Tiemersma E. Emergence and resurgence of meticillin-resistant Staphylococcus aureus as a public-health threat. Lancet 2006; 368:874-85.
58. Garner JS. Guideline for isolation precautions in hospitals. The hospital infection control practices advisory committee. Infect Control Hosp Epidemiol 1996; 17:53-80.

59. Cookson BD. The emergence of mupirocin resistance: a challenge to infection control and antibiotic prescribing practice. J Antimicrob Chemother 1998; 41:11-8.

60. Santos KRN, Teixeira LM, Bravo Neto GP, Fonseca LS, Gontijo Filho PP. Mupirocin- and Methicillin-Resistant Staphylococcus aureus Spreading in an Intermediate-Care Unit in a Brazilian Hospital. Letter to the editor Infect Control and Hosp Epidemiol 1998; 19(9):622-3.

61. Gorwitz RJ, Jernigan DB, Powers JH, Jernigan JA and Participants in the CDC Convened Experts' Meeting on Management of MRSA in the Community. Strategies for clinical management of MRSA in the community: Summary of an experts' meeting convened by the Centers for Disease Control and Prevention. 2006. Available at http://www.cdc.gov/ncidod/dhqp/ ar_mrsa_ca.html.

62. Ruhe JJ, Smith N, Bradsher RW and Menon A. Community onset methicillin- resistant Staphylococcus aureus skin and soft-tissue infections: impact of antimicrobial therapy on outcome. Clin Infect Dis 2007; 44:777-84.

63. Miller LG, Quan C, Shay A et al. A prospective investigation of outcomes after hospital discharge for endemic, communityacquired methicillin-resistant and -susceptible Staphylococcus aureus skin infection. Clin Infect Dis 2007; 44:483-92.

64. Robinson DA, Kearns AM, Holmes A. Re-emergence of early pandemic Staphylococcus aureus as a community-acquired methicillin-resistant clone. Lancet 2005; 365:1256-8.

65. Diep BA, Gill SR, Chang RF et al. Complete genome sequence of USA300, an epidemic clone of community-acquired methicillin-resistant Staphylococcus aureus. Lancet. 2006; 367(9512):731-9. 